\title{
ROLE OF DIFFUSION - WEIGHTED MAGNETIC RESONANCE IMAGING IN CHARACTERIZATION OF VERTEBRAL BONE MARROW PATHOLOGICAL LESIONS By
}

Khaled Lakouz* ,Hesham Radwan*, A.AllahAlmaamoon Sarhan** and Rania Elmolla*. (Radiodiagnosis* and Neurology** departments, Faculty of Medicine, ZagazigUniversity). \begin{abstract}
AIM: To evaluate the role of diffusion weighted magnetic resonance imaging in characterization of vertebral bone marrow pathological lesions.

MATERIALS AND METHODS: Forty patients with bone marrow abnormal MRI signal intensity were enrolled in the study and upon MRI finding they wear grouped into four groups. DWI was performed with b values of 0 and $500 \mathrm{~s} /$ $\mathrm{mm}^{2}$. Results of the histo-pathological evaluation or MRI follow up or isotope were compared with the DWI results. Apparent diffusion coefficient (ADC) values were calculated.

RESULTS: All cases of malignant collapse (4 cases 10\%) were hyper intense on DWIs and hypo intense on ADC map with mean ADC $(0.8 \pm 0.33 \times 10-3 \mathrm{~mm} 2 / \mathrm{s})$. All benign osteoporotic collapse cases ( 7 cases $17.5 \%)$ were hypo intense ( 3 cases) or iso to hypo intense ( 4 cases) on DWIs and all wear hyper intense on ADC with mean ADC $(1.64 \pm 0.33 \mathrm{x}$ 10-3 mm2/s). Twelve cases with endplate changes, the eight infectious spondylitis recorded mean ADC value (1.03 $\pm 0.33 \times 10-3 \mathrm{~mm} 2 / \mathrm{s})$. The remaining, 4 cases $(10 \%)$ with degenerative Modic I end plate changes recorded ADC value $(1.76 \pm 0.33 \times 10-3 \mathrm{~mm} 2 / \mathrm{s})$. Also (3 cases) malignant bone marrow infiltration without collapse were hyperintense on DWIs and hypointense on ADC map with mean ADC $(0.8 \pm 0.33 \times 10-3 \mathrm{~mm} 2 / \mathrm{s})$. The mean ADC in hemangioma was $(1.9 \pm 0.33 \times 10-3 \mathrm{~mm} 2 / \mathrm{s})$ and in ABC $(1.93 \pm 0.33 \times 10-3 \mathrm{~mm} 2 / \mathrm{s})$. DW study of 4 cases respond to therapy recorded

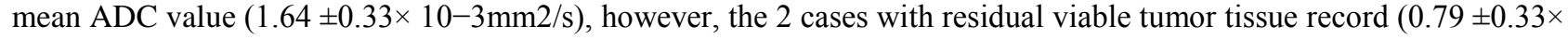
$10-3 \mathrm{~mm} 2 / \mathrm{s})$. DWI and ADC values have high sensitivity and specificity in differentiating benign from malignant lesions and in post therapy follow up.

CONCLUSIONS: DWI with quantitative ADC measurements Using b value $\left(\mathrm{b}=500 \mathrm{~s} / \mathrm{mm}^{2}\right)$ can be useful in differentiating benign from malignant bone marrow lesions, differentiated between causes of end plate changes and be used in post therapy follow up.

Keywords: Diffusion weighted imaging; Bone marrow; Vertebral compression fractures; Osteomyelitis; Therapy monitoring.
\end{abstract}

\section{INTRODUCTION}

$\mathbf{T}$ he spine is one of the most common organs imaged using magnetic resonance. Typical benign lesions are hemangiomas, edema in degenerative disease, osteoporotic fractures with edema and spondylodiscitis as an inflammatory process. Atypical hemangiomas and excessive edema due to degenerative processes can pose problems in the differential diagnosis of malignancy(1). The most common malignant diseases are metastases, neoplastic vertebral fractures, myeloma, primary malignant bone tumors, primary or secondary lymphoma and diffuse marrow diseases such as leukemia (2).

The differentiation between benign and malignant vertebral collapse is often problematic, particularly in elderly patients who are predisposed to benign compression fracture caused by osteoporosis. Benign vertebral fractures occur in approximately one third of cancer patients, and metastatic vertebral fracture account for $39 \%$ of bony metastases in patients with primary neoplasm. Interpretation of the lesion will be more difficult if there is a known primary malignancy elsewhere(3).

The degenerative disease with edema usually presents as band-like edema along the end-plates. Sometimes edema may affect the whole vertebral body, thus raising the question of whether a neoplastic process may be present (2). The cellular structure of a tumor is considered to be an indicator of tumor aggressiveness, and to influence the response to tumor therapy. DWI is considered to be a potential tool for monitoring treatment effects by exploiting the structural differences of biologic tissue. DWI depicts differences in diffusion and in membrane integrity between viable and necrotic tumor and thus, may be used to monitor tumor viability during treatment (4). In spite of its high sensitivity, conventional MRI is of only limited specificity in the evaluation of bone marrow alterations, so, these MR-sequences (T1, T2 and STIR) are in general not enough to differentiate between different causes of vertebral abnormal bone marrow signal alteration (5).

Diffusion-weighted magnetic resonance imaging (DWI) is a well-established magnetic resonance imaging (MRI) technique, in which the MRI signal intensity is influenced by selfdiffusion, i.e., microscopic stochastic Brownian motion of water molecules caused by the molecular thermal energy. DWI can provide information about the microscopic structure and organization of biological tissue and, thus, can depict various pathological changes in organs or tissues (2). The contrast achieved by this technique can be used as a non invasive 
investigation for tissue characterization. A hypo intense or iso intense signal was associated with benign edema, whereas tumor showed hyper intensity in contrast to normal surrounding marrow. The apparent diffusion coefficient is a quantitative measure of diffusion in diffusion weighted $\operatorname{EPI}(\mathbf{6})$.

\section{MATERIALS AND METHODS \\ Patients}

Forty patients presenting by vertebral collapse and/or altered MR signal intensity in one or more vertebral body on conventional MR sequences were included in this study. They were 18 females (45\%) and 22 males (55\%). Their ages ranged from 2 to 70 years and mean age was 49.4 \pm 16.7 years. The study was performed during the period from December 2011 to June 2013. All our cases were referred from Neurosurgery and Radiotherapy Departments. The patients were subjected to the following:

1.Clinical history taking

2.Imaging modalities

MRI study technique

A-Conventional MRI

- Sagittal images 4mm section thickness, 380mm FOV, $258 \times 512$ matrix, and the following sequences:T1 and T2WIs(600/12 and 5500/120 TR/TE respectively).- Axial images were acquired with 4-mm section thickness, 380-mm FOV, 192 $\mathrm{x} 256$ matrix, and the following sequences: T1andT2WIs(750/15 and 5500/120 TR/TE respectively).

B- Diffusion MRI:

- A fast scout scan in sagittal and axial planes were obtained and the volume of interest was positioned within each lesion, carefully excluding other structures. DW-MRI were obtained using a multi-section single shot spin echo EPI sequence with diffusion sensitivities of $b$ values $=0$ and $500 \mathrm{~s} / \mathrm{mm}^{2}$. The diffusion gradient were applied sequentially in the three orthogonal directions(TR/TE:1600/95ms) matrix(176x256), thickness $(6 \mathrm{~mm})$, gap $(1 \mathrm{~mm})$, Fov(40x20), acquision time(4), and a standard phased array surface receiver coil for imaging the spine were used. ADC maps were formed automatically (ROI) approximately $10 \mathrm{~mm}$ were placed in the center of the lesion to obtain ADC value with $b$ values 0 and $500 \mathrm{~s} / \mathrm{mm} 2$.

\section{Histopathological correlation}

The final diagnosis were obtained from the pathological results of the surgical specimen in indicated patients, complementary post contrast MRI in suspected cases of infection, and isotope MRI in post therapy cases, and isotope follow up for post therapy cases, however 3 months follow up MRI in some selected cases.

\section{Statistical analysis}

Data is expressed as mean (SD) unless otherwise indicated one way analysis of variance (ANOVA) was used to compare the mean values between the studied group. For significant finding a post -ANOVA pair wise comparison of mean was concluded $\mathrm{p}$ value $<0.05$ was considered significant (7). Also we use receiver's operating curve (ROC) to characterize benign and malignant lesions. Validity of (DW- MRI) for diagnosis of causes of vertebral bone marrow lesion was tested by sensitivity, specificity, Positive Predictive Value (PPV) and Negative Predictive Value (NPV)\& measure of agreement (Kappa test) (7).

\section{RESULT}

Acording to MRI finding as in table(1) patients are divided into 4 groups:

A: Patients with vertebral collapse(11 cases) osteoporotic and malignant

B: Patients with endplate changes(12 cases) Modic I and Spondylitis

C:Patients with non collapsed diffuse abnormal bone marrow SI lesion(10 cases) Malignant \& benign(atypical hemangioma and $\mathrm{ABC}$ )

D: Patient on follow up post therapy (7 cases) Residual and necrotic tumor tissue.

Group A patients: Eleven patient (27.5\%) were included in this group and are presented with vertebral collapse within 4 to 6 weeks. $72.7 \%$ of malignant cases show involvement of pedicle and posterior neural element, however we found one cases of pathologically proved atypical hemangiomas and one case of $\mathrm{ABC}$ showed involvement of posterior neural element. $63.6 \%$ of malignant cases show convex bulge of the posterior cortex of the vertebra, which not found in osteoporotic cases. However, presence of epidural and/or paraspinal mass was found only in $45 \%$ malignant cases in our study, this is because 7 of malignant cases were under therapy and 2 of them were operated for decompression. In osteoporotic cases $71.4 \%$ showed focal band like (of low signal intensity on T1WI) adjacent to endplate. In diffusion weighted study,(table 2). All cases of malignant collapse (4 cases $10 \%$ ) were hyperintense on DWIs and hypointense on ADC map with mean ADC $(0.8 \pm 0.33 \times 10-3 \mathrm{~mm} 2 / \mathrm{s})$. All benign osteoporotic collapse cases ( 7 cases $17.5 \%$ ) were hypointense (3 cases) or iso to hypointense (4 cases) on DWIs and hyperintense on ADC with mean ADC $(1.64 \pm 0.33 \times 10-3$ $\mathrm{mm} 2 / \mathrm{s}$ ), (tables $\mathbf{2 \& 3}$ ). We found that 2 of the previously diagnosed cases by conventional MRI as malignant vertebral collapse (one case has hepatocellular carcinoma and the other presented with paraspinal soft tissue component) were proved to be osteoporotic by DWI and ADC value 
and this confirmed by histopthology and follow up.

Group B patients included 12 patient $(30 \%)$ presented with vertebral end plate changes. All cases presented with end plate irregularity with decreased signal intensity on T1-weighted images and increased signal intensity on T2weighted images in the adjacent vertebral bodies. Epidural and/or paraspinal mass was found in $75 \%$ of spondylodiscitis,(table,1). In diffusion weighted study, vertebral bone marrow of ( 8 cases $20 \%$ ) confirmed to be infectious spondylitis displayed hyperintense SI on DWIs and hypointense on ADC map with mean ADC value $(1.03 \pm 0.33 \times 10-3 \mathrm{~mm} 2 / \mathrm{s})$, however, 4 case $(10 \%)$ of degenerative Modic I end plate changes showed hypointense ( 2 case) or iso to hypointense (2 case) SI on DWIs and iso to hyperintense(3 case) or hyperintense (1 case) on ADC map with mean ADC value $(1.76 \pm 0.33 \times 10-3 \mathrm{~mm} 2 / \mathrm{s})$, (tables 2\&3). We found one case of previously diagnosed degenerative end plate (Modic I) due to absence of any soft tissue collections, or clear infectious symptoms or history, proved to be restricted in DWIs and of low ADC value going with spondylitis which confirmed with complementary Gd-DTPA MRI displayed post contrast enhanced end plate. there is only limited value in using DWI to differentiate between infectious and malignant vertebral lesions, with approximately $63 \%$ sensitivity, specificity and accuracy

Group C patients included 10 cases presented by abnormal vertebral bone marrow signal intensity changes without collapse. Three cases of atypical hemangiomas displayed low SI on T1WIs. The two cases of ABC are typically hyperintense on $\mathrm{T} 2$-weighted imaging and hypointense on T1-weighted imaging with Fluidfluid and hemorrhagic component as well as being in the posterior neural elements,(table1). We found that two cases diagnosed by conventional MRI as malignant infiltration (one involve the posterior neural arch and the other has epidural component compressing the ventral aspect of the thecal sac) proved to be atypical hemangiomas showing facilitated diffusion on DWI with high ADC value and they are confirmed by MRI follow up and post operative decompression biopsy respectively. While malignant bone marrow infiltration cases (3) were hyperintense on DWIs and hypointense on ADC map with mean ADC $(0.8 \pm 0.33 \times 10-3 \mathrm{~mm} 2 / \mathrm{s})$. All benign cases $(5)$ atypical hemangiomas, and (2) ABC were hypointense on DWIs and hyperintense (except one case of atypical hemangioma displayed isointense signal) on ADC with mean ADC (1.9 \pm $0.33 \times 10-3 \mathrm{~mm} 2 / \mathrm{s})$ in hemangioma and mean ADC value $(1.93 \pm 0.33 \times 10-3 \mathrm{~mm} 2 / \mathrm{s})$ in $\mathrm{ABC}$. In this study we found that, DWI and conventional MRI are equivocal in diagnosis of the two cases of ABC due characteristic fluid fluid levels and high sensitivity to the hemorrhagic component on conventional MRI which display bright high signal on DWIs (tables $2 \mathbf{8 3}$ ).

Group D patients included 7 cases of previously diagnosed malignant vertebral bone marrow lesions (4 cases of lymphoma, one case of locally aggressive chordoma and 2 cases of vertebral metastasis) they finished their treatment course (surgical treatment, radio or chemotherapy or combination). All included patient finished their regimen within 4 to 6 weeks. All cases on conventional MR Imaging displayed low SI on T1 WIs and high SI on T2WIs (except one case was isointense and another on was hypointense on T2WIs) (table1), While in DW study the 4 cases proved being respond to therapy displayed hypointense SI (except one case was iso intense) on DW sequences and hyperintense (except one case was isointense)on ADC map with mean ADC value $(1.64 \pm 0.33 \times 10-3 \mathrm{~mm} 2 / \mathrm{s})$, however, the 2 cases with residual viable tumor tissue showed hyper and isointense DWIs and hypointense on ADC map with mean ADC value (0.79 $\pm 0.33 \times$ $10-3 \mathrm{~mm} 2 / \mathrm{s})$. In DW study two of 4 cases diagnosed as post therapy residual malignant infiltration by conventional MRI proved to be facilitated on DWI with ADC value above $1.52 \times 10-3 \mathrm{~mm} 2 / \mathrm{s}$, (tables,2,3) which is going with increased fluid component of tumor necrosis and this confirmed by isotope scan and follow up. 
Table (1): Conventional MRI secondary findings in the 40 patients in this study:

\begin{tabular}{|c|c|c|}
\hline MRI Finding & No. of patients & Percent \% \\
\hline Involvement of posterior neural arch & $10 / 40$ & 25 \\
\hline Vertebral collapse & $11 / 40$ & 27.5 \\
\hline $\begin{array}{l}\text { Presence of epidural and/or para-spinal soft } \\
\text { tissue mass }\end{array}$ & $11 / 40$ & 27.5 \\
\hline Convex bulge of posterior cortex & $7 / 40$ & 17.5 \\
\hline $\begin{array}{l}\text { Focal band like (of low SI on T1WI) near } \\
\text { end-plate }\end{array}$ & $4 / 40$ & 10 \\
\hline End plate changes & $12 / 40$ & 30 \\
\hline
\end{tabular}

Table (2):Diffusion Weighted MRI Signal changes in the 40 patients in this study:

\begin{tabular}{lccc}
\hline Signal & Hypointense & Isointense & Hyperintense \\
\hline Diffusion & $16(40 \%)$ & $8(20 \%)$ & $16(40 \%)$ \\
\hline $\begin{array}{l}\text { ADC map } \\
(\mathrm{b}=500)\end{array}$ & $17(42.5 \%)$ & $4(10 \%)$ & $19(47.5 \%)$ \\
\hline
\end{tabular}

Table (3): ADC values in the 40 patients in this study:

\begin{tabular}{|c|c|c|c|c|}
\hline Groups & $\begin{array}{l}\text { Provisional } \\
\text { diagnosis by DWI }\end{array}$ & $\begin{array}{l}\text { No. } \\
\text { of } \\
\text { patients }\end{array}$ & $\begin{array}{l}\text { Range of ADC in each } \\
\text { lesion group } \\
(\mathrm{x} 10-3 \mathrm{~mm} 2 / \mathrm{sec}) \\
(\mathrm{b}=500)\end{array}$ & $\begin{array}{l}\text { Mean ADC value } \\
{[x- \pm \text { SD }](x 10-3} \\
\mathrm{mm} 2 / \mathrm{sec}) \\
(\mathrm{b}=500)\end{array}$ \\
\hline \multirow[t]{2}{*}{ Group A } & $\begin{array}{l}\text { Osteoporotic } \\
\text { collapse }\end{array}$ & 7 & $1.50-1.93$ & $1.64 \pm 0.15$ \\
\hline & Malignant collapse & 4 & $0.68-0.88$ & $0.79 \pm 0.06$ \\
\hline \multirow[t]{2}{*}{ Group B } & $\begin{array}{l}\text { Degenerative } \\
\text { osteoporosis Modic } \\
\text { I }\end{array}$ & 4 & $1.23-1.82$ & $1.76 \pm 0.17$ \\
\hline & $\begin{array}{l}\text { Infection } \\
\text { (spondylodiscitis) }\end{array}$ & 8 & $0.78-1.34$ & $1.03 \pm 0.42$ \\
\hline \multirow{3}{*}{$\begin{array}{l}\text { Group C: } \\
\text { C:1-Benign } \\
\text { C-2-Malignant }\end{array}$} & \multirow{2}{*}{$\begin{array}{l}\text { *Hemangioma } \\
* * \text { Aneurysmal bone } \\
\text { cyst }\end{array}$} & 5 & $1.41-2.36$ & $1.9 \pm 0.34$ \\
\hline & & 2 & $1.87-1.99$ & $1.93 \pm 0.08$ \\
\hline & $\begin{array}{l}\text { Malignant } \\
\text { infiltration }\end{array}$ & 3 & $0.77-0.84$ & $0.81 \pm 0.04$ \\
\hline \multirow{3}{*}{$\begin{array}{l}\text { Group D: } \\
\text { Post therapy }\end{array}$} & Residual & 2 & $0.68-0.89$ & $0.79 \pm 0.15$ \\
\hline & $\begin{array}{l}\text { Necrotic } \\
\text { tissue }\end{array}$ & 5 & $1.52-1.94$ & $1.64 \pm 0.18$ \\
\hline & $P$ value & & & $0.000 * * *$ \\
\hline
\end{tabular}

In our results we found (as shown in tables $\mathbf{4 \& 5}$ ) conventional MRI have high sensitivity $100 \%$ and specificity 86.2 in differentiating benign from malignant causes of vertebral bone marrow lesion while DWI and ADC values have more higher sensitivity and specificity in differentiating benign from malignant vertebral bone marrow lesion $100 \%$ and $90.3 \%$, respectively, while PPV and NPV were $75 \%$ and $100 \%$ respectively, but low sensitivity and specificity in differentiating infection from malignancy $63 \%$ and $63 \%$, respectively. 
Table (4): Validity of conventional MRI in the diagnosis of vertebral bone marrow lesions.

\begin{tabular}{llll}
\hline & Malignant group & Benign group & Total \\
\hline$+\mathrm{Ve}$ & True $+\mathrm{Ve}$ & False $+\mathrm{Ve}$ & 15 \\
& 11 & 4 & \\
& False $-\mathrm{Ve}$ & True-ve & 25 \\
$-\mathrm{Ve}$ & 0 & 25 & \\
& 11 & 29 & 40 \\
\hline Total & & \\
\hline Sensitivity $=100 \%$, Specificity $=86.2 \%$, PPV $=73.3 \%$, NPV $=100 \%$
\end{tabular}

Table (5): Validity of ADC in the diagnosis of vertebral bone marrow lesions at a cut value of $0.95 \times 10-$ $3 \mathrm{~mm} 2 / \mathrm{sec}$

\begin{tabular}{llll}
\hline & Malignant group & Benign group & Total \\
\hline$+\mathrm{Ve}$ & True $+\mathrm{Ve}$ & False $+\mathrm{Ve}$ & 12 \\
\hline & 9 & 3 & \\
\hline & & True-ve & 28 \\
& False $-\mathrm{Ve}$ & 28 & \\
\hline Total & 9 & 31 & 40 \\
\hline $\begin{array}{l}\text { Sensitivity }=100 \%, \\
\text { agreement. }\end{array}$ & Specificity=90.3\%, & PPV $=75 \%, \mathrm{NPV}=100 \%, \mathrm{P}$ value $<0.003$ so there is excellent \\
\hline
\end{tabular}

\section{DISCUSSION}

Pathological lesions usually replace normal components of the vertebral bone marrow. Such replacement could be neoplastic cells, inflammatory cells, water, as well as blood degradation products. Therefore, the signal detected would be changeable to a certain degree depending on the amount and type of cells. Neoplastic and inflammatory cells usually replace all the normal fat in the bone marrow (8). In opposed phase gradient echo, fat and water resonate at different frequencies. By choosing the appropriate TE we can subtract fat from water during in and out of phase sequences (9). This is most profound when the amount of water and fat in each voxel is similar, as in the bone marrow. Susceptibility differences between trabecular bone, soft tissue and blood degradation products also create localized distortions of the magnetic field which induce strong inhomogeneities in the static magnetic field (10).

Conventional MRI sequence signal changes are usually subjective depending on morphology and predominant site of signal changes involvement. However, this sometimes does not solve the problem (11).

Diffusion weighted MR sequences provide dynamic and microscopic information to supplement the static and macroscopic information provided by conventional sequences (12). It is a non invasive imaging technique which is suitable for probing the physical structure of a biologic tissue at a microscopic level and it exploits the random, translational motion of water protons in a biologic tissue, which reflects the tissue specific diffusion capacity and can be used for tissue characterization (13). The diffusion capacity is indirectly proportional to the amount of diffusion barriers, such as membranes, tight junctions, fibers, macromolecules and cell organelles (14).

This study included 40 patients with vertebral bone marrow signal alteration of different causes. The most common clinical presentation in MRI of the spine is back pain. Less commonly, the patient may present with sciatica or brachialgia, paraparesis and paraplegia. Rarely, the patient may present with incontinence.(3), that were nearly the same symptoms presented in the patients in this study, as well as 7 cases who received therapy and were under follow up within one month after last therapeutic dose. The lumber vertebrae ware the most common level of affection, with no level of predilection.

The bone marrow is -in generalcomposed of fatty tissue, which appears hyper intense on T1WI and T2WI. In case of collapse, 
tumor or infection; infiltration, replacement and depletion of fatty bone marrow occur resulting in intermediate to hypointense signals on T1WI and hyperintense signals on T2WI (5). This was in agreement with our results, where 35 cases of the 40 patients showed low signal intensity of the affected vertebra on T1WI $(87.5 \%)$ and 28 cases of the 40 patients showed increased signal intensity on T2WI (70\%).

Acording to MRI finding patients are divided into 4 groups:
A: Patients with vertebral collapse(11 cases) osteoporotic and malignant

B: Patients with endplate changes(12 cases) Modic I and Spondylitis

C:Patients with non collapsed diffuse abnormal bone marrow SI lesion(10 cases) Malignant \& benign(atypical hemangioma and $\mathrm{ABC}$ )

D: Patient on follow up post therapy ( 7 cases) Residual and necrotic tumor tissue.

Eleven patient $(27.5 \%)$ were included in group A and are presented with vertebral collapse within 4 to 6 weeks:
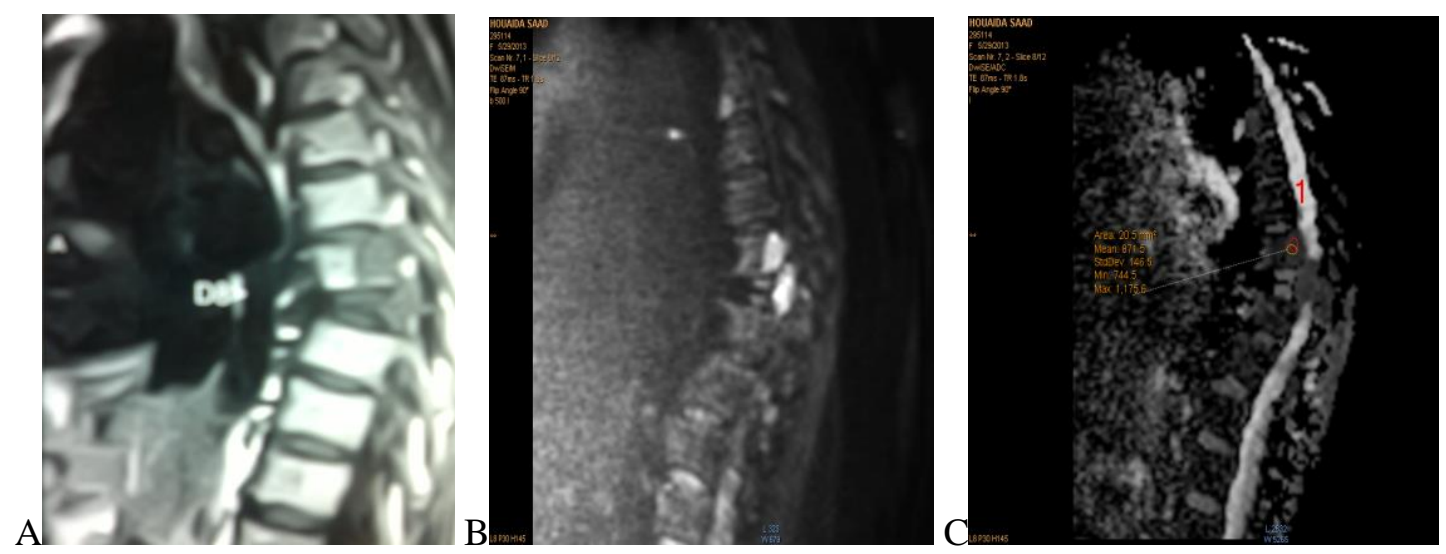

Fig(1)50-year-old female of malignant collapse(A): Sagittal T1WI showed reduced cranio-caudal height of D8 vertebral body with isointense bone marrow signal,and convex posterior border(b):Sagittal DWI shows hyperintensity of the affected vertebra as well as D7 and low signal intensity $(C)$ on $A D C$ map $(b=500)$. ADC value $(b=500)$ is $0.78 \times 10-3 \mathrm{~mm} 2 / \mathrm{s}$, denoting restricted diffusion and D8 malignant collapse of metastatic breast cancer.

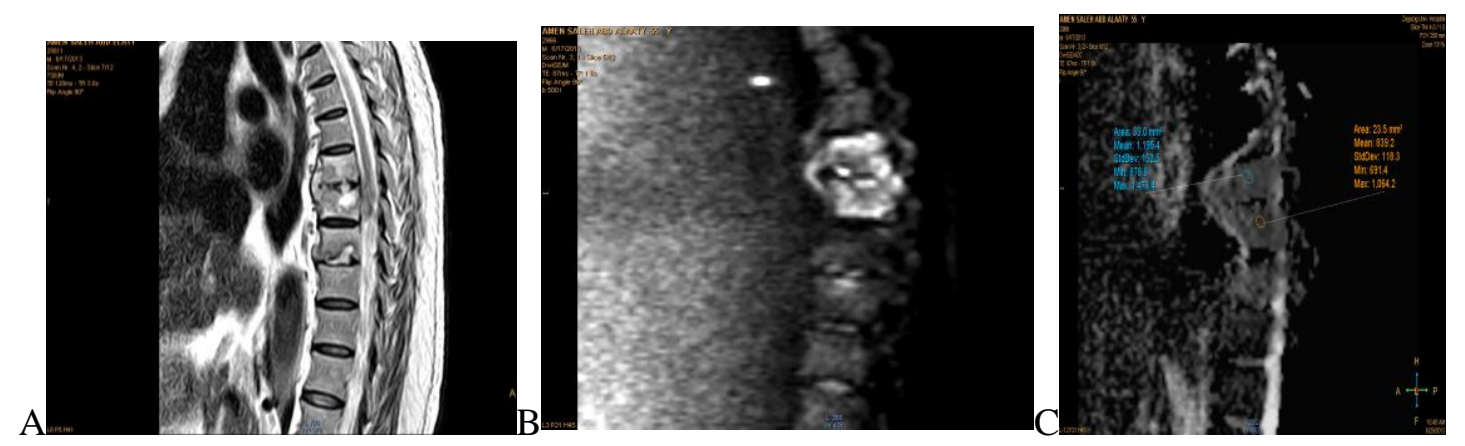

Fig(2)60-year-old male of infectious spondylodiscitis with intraosseous abscess formation. Sagittal T2WI(A) show hypoinensity of the affected vertebral bodies, irregular vertebral end plates, with D9 intraosseoes cavitary hyperintense lesion with affection of in betwwen disc and loss of the nuclear intercleft.(b):Sagittal DWI shows hyperintensity of the affected vertebra as well as D7 and low signal intensity on ADC map(C) and more lower SI in the cavitary lesion ADC value $(b=500)$ is $1.12 \times 10-3 \mathrm{~mm} 2 / \mathrm{s}$ and $0.83 \times 10-3 \mathrm{~mm} 2 / \mathrm{s}$ in the center of the cavitary lesion denoting restricted diffusion. 

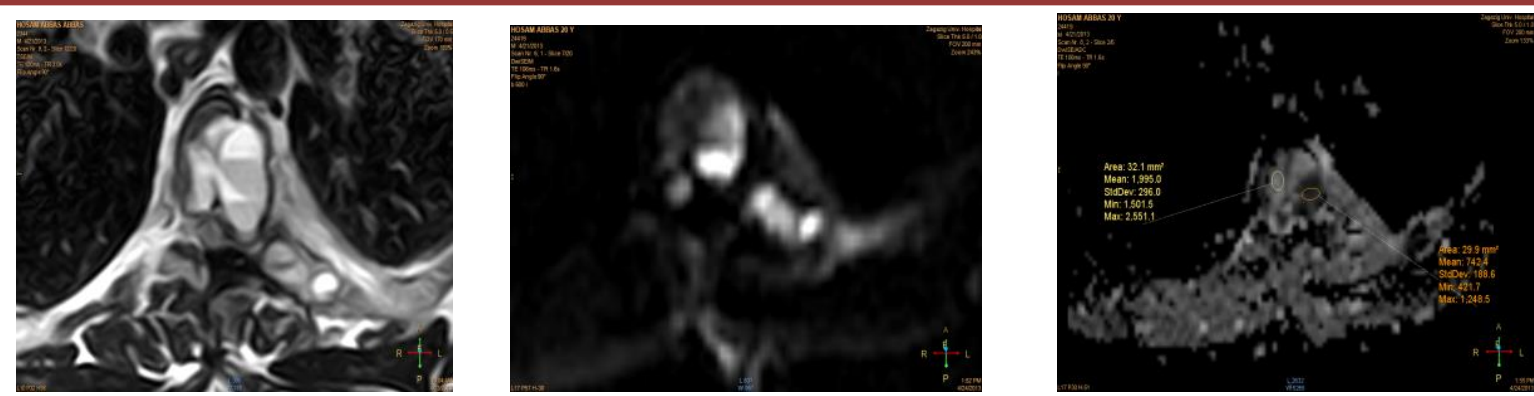

Fig(3)2-year-old male with aneurysmal bone cyst. Axial T2WI(A) show hyperinensity of D5 vertebral body and its LT posterior neural arch with multiple fluid fluid levels, Axial DWI(b) shows hypointensity of the affected vertebra denoting unrestricted diffusion, however hemorrhagic areas show hyperintense signal of restricted diffusion. ADC map (C) showed a part from the dark low SI of restricted diffusion due to hemorrhagic component, the rest of D5 showed high signal intensity denoting unrestricted diffusion, ADC value $(\mathrm{b}=500)$ is $1.99 \times 10-3 \mathrm{~mm} 2 / \mathrm{s}$. and of the hemorrhagic component is $0.74 \times 10-3 \mathrm{~mm} 2 / \mathrm{s}$.
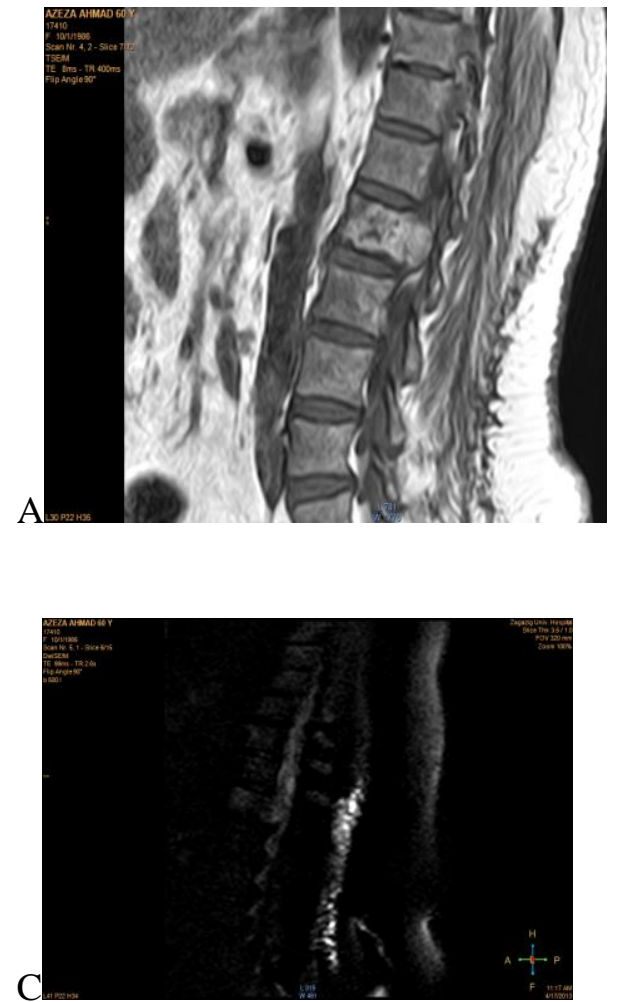

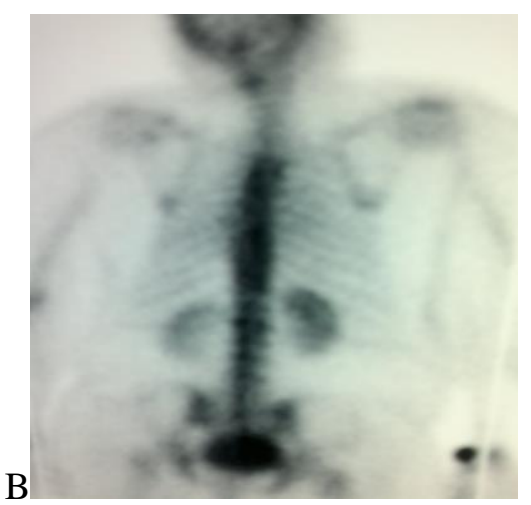

D

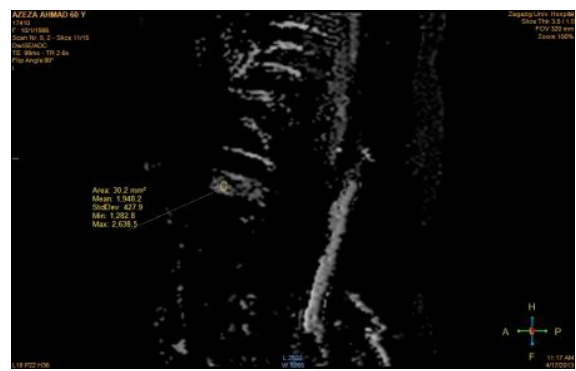

Fig(4)60-year-old female with past history of operated cancer breast and L1 giant hemangioma. Sagittal T1WI(A) show diffuse infiltrative bone marrow abnormal SI lesion involving L1 vertebral body and its posterior neural element displaying heterogeneous hypo and hyperintensity, with convex posterior border,(b) Iso-top study P-A view showed normal radiotracer uptake of the spine(C) Sagittal DWI shows isointensity of the affected vertebra.(E) ADC map showed high signal intensity of the affected vertebra denoting facilitated diffusion. ADC value $(\mathrm{b}=500)$ is $01.94 \times 10-3 \mathrm{~mm} 2 / \mathrm{s}$. 

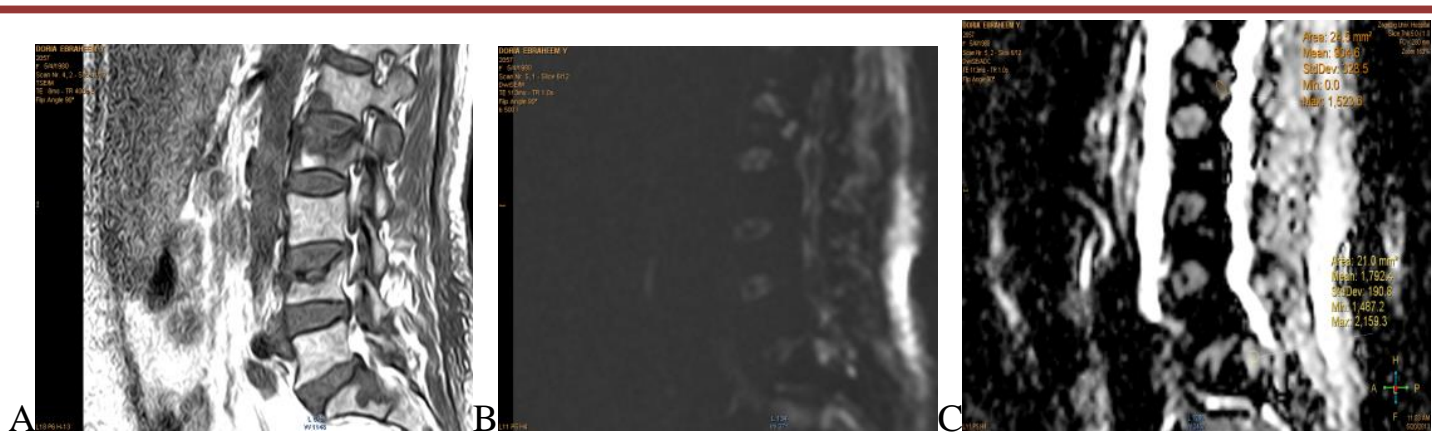

Fig(5)70-year-old female with history of metastatic bronchogenic carcinoma finished palliative radiotherapy(29 days ago).sagittal T1WI(A) showed reduced cranio-caudal height of L2 and L4 vertebrae with diffuse infiltrative bone marrow abnormal SI lesion involving L2 and L4 as well as S1 vertebral bodies displayed hypointensity on T1WI.(B) Sagittal DWI shows high signal intensity of L2 and S1 vertebrea. On ADC (C) showed hypointense signal of Restricted diffusion in L2 with ADC value (b=500) $0.9 \times 10-3$ $\mathrm{mm} 2 / \mathrm{s}$, denoting still viable tumor tissue, as well as, Hyperintense signal of facilitated diffusion in S1 with ADC value $(b=500) 1.83 \times 10-3 \mathrm{~mm} 2 / \mathrm{s}$ denoting fluid signal of tumor necrosis. NB:L4 show no signal changes in DW study(chronic collapse.)

Conventional MRI provides morphological features that are considered to be suggestive of malignant infiltration including involvement of the pedicles, the presence of an epidural and/or paraspinal soft-tissue mass and convex bulge involving the posterior cortex of the vertebral body (15).

In metastatic compression fractures a higher frequency of abnormal signal intensity of the pedicle $(85 \%)$ or posterior element $(59 \%)$ (16). Also the convex bulge of the posterior cortex of the vertebra have $70 \%$ sensitivity and $80 \%$ specificity (17) this is going with our result, where $72.7 \%$ of malignant cases show involvement of pedicle and posterior neural element, however we found one cases of pathologically proved atypical hemangiomas (case 4) and a one case of ABC showed involvement of posterior neural element (case 3 ). $63.6 \%$ of malignant cases show convex bulge of the posterior cortex of the vertebra, which not found in osteoporotic cases. Presence of an epidural mass have $80 \%$ sensitivity and $100 \%$ specificity (17). In our results the presence of epidural and/or paraspinal mass was found only in $45 \%$ malignant cases, this is because 7 of malignant cases were under therapy and 2 of them were operated for decompression of the epidural component. We found also a known patient with treated cancer breast presented with epidural soft tissue component proved to be atypical giant hemangioma.

Jung, et al (18), found that band like of low signal intensity on T1- and T2-weighted images was more common in acute osteoporotic compression fractures than metastatic compression fractures found in $93 \%$ of acute osteoporotic fractures. However we found this sign only in $71.4 \%$ this is because of small number of cases ( 7 cases).

Diffusion-weighted sequences provide dynamic and microscopic information to supplement the static and macroscopic information provided by conventional sequences. Diffusion-weighted sequences reflect the random movement of water molecules (which includes both intracellular and extracellular movement, as well as transcellular and intracapillary movement) (19).

Pathological bone marrow exhibits diffusivities, ranging from about 0.7 to $1.0 \times 10^{-3}$ $\mathrm{mm}^{2} / \mathrm{s}$ in metastases as well as malignant fractures. In acute osteoporotic and traumatic fractures, ADCs of 1.0 to $2.0 \times 10^{-3} \mathrm{~mm}^{2} / \mathrm{s}$ were found. $(5,17,19-21)$.

Baur et al.,(22) reported that ostreoporotic and traumatic compression fractures are hypointense in DWI due to edema and hemorrhage that lead to increase of extracellular volume and the water mobility increased; therefore the mean ADC value is high (1.96 \pm $0.33 \times 10-3 \mathrm{~mm} 2 / \mathrm{s})$. They also reported that neoplastic compression fractures are hyperintense due to increased cellularity that lead to decreased water mobility; therefore the mean $\mathrm{ADC}$ value is low $(0.69 \pm 0.33 \times 10-3 \mathrm{~mm} 2 / \mathrm{s})$.

However, Castillo et al., (15) stated, that diffusion-weighted MR imaging of the spine showed no advantage in the detection and characterization of vertebral metastases as compared with non-contrast conventional MRI. A possible explanation is that this sequence contains information from T2-effect that is why all lesions that were hyperintense in DWI were also 
hyperintense in T2WI (19) reported that quantitative $\mathrm{ADC}$ mapping is required to remove the T2 effect (shine through) to improve differentiation between benign and malignant causes of vertebral collapse. The accuracy of ADC values depends on many factors as $b$ value that should be above $150 \mathrm{~s} / \mathrm{mm} 2$. That was going with our results where all cases of malignant collapse (4 cases 10\%) were hyperintense on DWIs and hypointense on ADC map, as shown in case number one, with mean $\mathrm{ADC}(0.8 \pm 0.33 \mathrm{x}$ 10-3 mm2/s), While, all benign osteoporotic collapse cases (7 cases $17.5 \%)$ were hypointense( 3 cases) or iso to hypointense (4 cases) on DWIs and hyperintense on ADC with mean ADC $(1.64 \pm 0.33 \times 10-3 \mathrm{~mm} 2 / \mathrm{s})$. In group A we found that 2 of the previously diagnosed cases by conventional MRI as malignant vertebral collapse (one case has hepatocellular carcinoma and the other presented with paraspinal soft tissue component) were proved to be osteoporotic by DWI and ADC value and this confirmed by histopthology and follow up.

Group B patients included 12 patient (30\%) and are presented with vertebral end plate changes. We agree with Byn (23) who found that all his cases of bone marrow adjacent to the vertebral end plate in both degenerative spine with fibrovascular change ( Modic type 1) and pyogenic spondylitis showed hypointense on T1WI and hyperintense on T2WI. In this study epidural and/or paraspinal mass was found in $75 \%$ of spondylodiscitis, so we agree with Jain et al., (24), who found that The pre and paravertebral abscesses are reported between 58 and $100 \%$ of pyogenic and tuberculus spondylodiscitis. Diffusion-weighted MR imaging of the vertebral bone marrow adjacent to the endplate showed low signal intensity reflecting increased apparent diffusion coefficient in all degenerative type 1 marrow changes, and hyperintense bone marrow reflecting decreased apparent diffusion coefficient in all pyogenic spondylitis (23). This is go hand in hand with our results as we found that vertebral bone marrow of ( 8 cases $20 \%$ ) confirmed to be spondylitis displayed hyperintense SI on DWIs and hypointense on ADC map with mean ADC value $(1.03 \pm 0.33 \times 10-3 \mathrm{~mm} 2 / \mathrm{s})$, however, 4 case $(10 \%)$ of degenerative Modic I end plate changes showed hypointense (2 case) or iso to hypointense (2 case) SI on DWIs and iso to hyperintense $(3$ case) or hyperintense ( 1 case) on ADC map with mean ADC value $(1.76 \pm 0.33 \times$ $10-3 \mathrm{~mm} 2 / \mathrm{s})$.Also in group $B$ one case of previously diagnosed degenerative end plate (Modic I) due to absence of any soft tissue collections, or clear infectious symptoms or history, proved to be restricted in DWIs and of low ADC value going with spondylitis which confirmed with complementary Gd-DTPA MRI displayed post contrast enhanced end plate. In a study done by Balliu (5) The mean ADC values from infectious spondylitis group (15 patients) were not statistically different from malignant lesions $(0.917 \pm 0.13 \times 10-3 \mathrm{~mm} 2 / \mathrm{s}) .(\mathbf{1 , 2 1 , 2 5})$

Pui et al., (25) reported that the ADC values of pyogenic spondylodiscitis are not significantly different than the ADCs from tuberculous spondylodiscitis. A possible explanation for this finding is that hypercellularity and the presence of macromolecules reduces the diffusivity in inflammatory tissue. This is go hand in hand with our results as we found that ADC value of cases of spondylitis range from 0.78 to $1.34(\mathrm{x} 10-3 \mathrm{~mm} 2 / \mathrm{sec})$ with mean ADC value $(1.03 \pm 0.33 \times 10-3 \mathrm{~mm} 2 / \mathrm{s})$., and $\mathrm{ADC}$ value of different cases of malignant infiltration range from 0.68 to $0.89(\mathrm{x} 10-3 \mathrm{~mm} 2 / \mathrm{sec})$ with mean $\mathrm{ADC}$ value $(0.79 \pm 0.33 \times 10-3 \mathrm{~mm} 2 / \mathrm{s})$ with many reading overlaps.

Group C patients include 10 cases presented by abnormal vertebral bone marrow signal intensity changes without collapse. Atypical hemangiomas that contain only a small or microscopic amount of fat are often difficult to distinguish from malignant lesions on conventional T1 and T2WIs(26). Also he reported that cases of aneurysmal bone cyst (ABC) is typically hyperintense on T2-weighted imaging and isointense or hypointense on T1WI. Fluidfluid levels may occur, but they are not pathognomonic of $\mathrm{ABC}$ (also seen in telangiectatic osteosarcoma) (26). $\mathrm{ABC}$ in the vertebrae tends to begin in the posterior elements and may spread through the pedicle into the vertebral body and epidural space (27). That was going with our results where 3 cases of atypical hemangiomas displayed low SI on T1Wis and the two cases of $\mathrm{ABC}$ are typically hyperintense on T2WIs and hypointense on T1WIs with Fluidfluid and hemorrhagic component as well as extending through the posterior neural elements. In this group we found that two cases diagnosed by conventional MRI as malignant infiltration (one involve the posterior neural arch and the other has epidural component compressing the ventral aspect of the thecal sac) proved to be atypical hemangiomas showing facilitated diffusion on DWI with high ADC value and they are confirmed by MRI follow up and post operative decompression biopsy respectively. Typical and atypical hemangiomas expressing non restricted diffusion in the form of low signal on DWI, while the metastases showed restricted 
diffusion in the form of high signal in DWI and low signal in ADC maps this is because of the contribution of water molecules within the vascular spaces $(\mathbf{2 8 , 2 9})$. The mean $\mathrm{ADC}$ value of hemangiomas was $1.54 \times 10-3 \mathrm{~mm} 2 / \mathrm{s}$ and the mean ADC value of metastatic bony lesions was $0.83 \times 10-3 \mathrm{~mm} 2 / \mathrm{s}(\mathbf{2 9})$.

Taskın et al.,(30) reported A statistically proven optimal ADC threshold of $0.96 \times$ $10-3 \mathrm{~mm} 2 / \mathrm{s}$ can be used for differentiating malignant from benign vertebral lesions. That was going with our results where malignant bone marrow infiltration cases(3) were hyperintense on DWIs and hypointense on ADC map with mean $\operatorname{ADC}(0.8 \pm 0.33 \times 10-3 \mathrm{~mm} 2 / \mathrm{s})$. All benign cases (5) atypical hemangiomas, and (2)ABC were hypointense on DWIs and hyperintense (except one case of atypical hemangioma displayed isointense signal) on ADC with mean $\mathrm{ADC}(1.9 \pm$ $0.33 \times 10-3 \mathrm{~mm} 2 / \mathrm{s})$ in hemangioma and mean ADC value $(1.93 \pm 0.33 \times 10-3 \mathrm{~mm} 2 / \mathrm{s})$ in $A B C$.

Group D patients include 7 cases of previously diagnosed malignant vertebral bone marrow lesions (4 cases of lymphoma, one case of locally aggressive chordoma and 2 cases of vertebral metastasis), and finished their treatment course (surgical treatment, radio or chemotherapy or combination). All included patient finished their regimen within 4 to 6 weeks. A recent study evaluating DWI monitoring of treatment response of vertebral metastatic deposits showed convincing changes from pre-chemotherapy bvalue hyperintensity to hypointensity following therapy (31). Ballon et al.,(32) reported two cases where the diffusivity of the treated lymphoma increased three-fold after therapy. Similar results were found by Buyn et al.,(4) who evaluated DWI of lymphoma patient prior and after tumor treatment. The ADC of successfully treated lymphoma increased significantly from $0.78 \times 10-3$ to $1.22 \times 10-3 \mathrm{~mm} 2 / \mathrm{s} \quad(\mathbf{4 , 3 2})$. This is going hand in hand with our results where we found all cases on conventional MR Imaging displayed low SI on T1 WIs and high SI on T2WIs (except one case was isointense and another one was hypointense on T2WIs). While in DW study 4 cases proved to be respond to therapy displayed hypointense SI (except one case was iso intense) on DW sequences and hyperintense (except one case was isointense) on ADC map with mean ADC value $(1.64 \pm 0.33 \times 10-3 \mathrm{~mm} 2 / \mathrm{s})$. On the other hand the 2 cases with residual viable tumor tissue showed hyper and isointense DWIs and hypointense on ADC map with mean ADC value $(0.79 \pm 0.33 \times 10-3 \mathrm{~mm} 2 / \mathrm{s})$. In group $\mathrm{D}$ patients we found that two of 4 cases diagnosed as post therapy residual malignant infiltration by conventional MRI proved to be facilitated on DWI with $A D C$ value above $1.52 \times 10-3 \mathrm{~mm} 2 / \mathrm{s}$ reflecting increased fluid component due to tumor necrosis and this confirmed by isotope scan and follow up .

Both Pui et al. (25) agree with Fawzy et al.,(21) who found that DWI and ADC values have high sensitivity and specificity in differentiating benign from malignant causes of vertebral collapse $100 \%$ and $93 \%$, respectively, but low sensitivity and specificity in differentiating infection from malignancy $63 \%$ and $63 \%$, respectively. This going in hand with our results as we found that DWI and ADC values have high sensitivity and specificity in differentiating benign from malignant causes of vertebral collapse $100 \%$ and $90.3 \%$, respectively, while PPV and NPV were $75 \%$ and $100 \%$ respectively, but low sensitivity and specificity in differentiating infection from malignancy $63 \%$ and $63 \%$, respectively.

Diffusion-weighted MR imaging found to have, $92 \%$ sensitivity, $90 \%$ specificity and accuracy of $85 \%$ in differentiation of benign and malignant vertebral compression fracture while PPV and NPV were $78 \%$ and $90 \%$ respectively(33)

In conclusion, DWI with quantitative ADC measurements could be easily added to a routine vertebral MR imaging protocol. It is an accurate method for characterization of different vertebral bone marrow lesions, as well as, therapy monitoring response to therapy. DWI also had the advantage of being fast and not requiring a contrast agent.

\section{REFERENCES}

1. Kessler J, Pawha P, Shpilberg K, et al., (2011): Diffusion weighted imaging facilitates detection of spinal multiple myeloma and assists in diagnosing equivocal lesions. American Society of Spine Radiology; 59:124-131.

2. Andrea BM. (2009): Malignant versus benign vertebral collapse: are new imaging techniques useful? Cancer Imaging ;9:S49-S51.

3. Andreas M, Friedrich K, Weidekamm C, et al., (2005): Diffusion weighted imaging of bone marrow pathologies. European Journal of Radiology; 55:74-83.

4. Byun WM, Shin SO, Chang Y, et al., (2002): Diffusion-weighted MR imaging of metastatic disease of the spine: assessment of response to therapy. AJNR;23(6):906-12.

5. Balliu E, Vilanova JC, Pel'aez I, et al., (2009): Diagnostic value of apparent diffusion coefficients to differentiate benign from malignant vertebral bone marrow lesions. European Journal of Radiology;69:560-566.

6. Baur A, et al., (1998): Diffusion-weighted MR imaging of bone marrow: differentiation of 
benign versus pathologic compression fractures. Radiology;207(2):349-56.

7. Norusis M; (1997): Statistical package for social science (SPSS) base 10 for windows. user's guide. Chichago ,IL :SPSS.

8. Osman OM, Fahmy YR, El-Oraby,AM, et al (2007): Role of Diffusion WIs and T2* GRE Pulse Sequences in Dubious Vertebral Marrow Pathological Lesions. Journal of the Egyptian Nat. Cancer Inst., Vol. 19, No. 4: 254-262.

9. Lingawi S and Ragab Y (2003): The Role of Opposed Phase Gradient Echo MR in Differentiating Benign from Malignant Vertebral Lesions, Presentation at European Congress of Radiology ECR- 2003 personal communication. 2005.

10. Weber M, Sharp J, Latta P, etal (2005): Magnetic resonance imaging of trabecular and cortical bone in mice: comparison of high resolution in vivo and ex vivo MR images with corresponding histology Eur J Radiology.53 (1): 96-102.

11. Majumdar S \& Genant HK (1995): A review of the recent advances in magnetic resonance imaging in the assessment of osteoporosis Osteoporos Int.5: 79-92.

12. Baur A, Dietrich O, Reiser M(2003): Diffusionweighted imaging of bone marrow: current status. Eur Radiol;13(7):1699-708.

13. Herneth AM, Friedrich K, Weidekamm C, et al (2005): diffusion weighted imaging of bone marrow pathologies. Eur J Radiol ;55:74-83.

14. Le Bihan DJ, (1998): Differentiation of Benign versus Pathologic Compression Fractures with Diffusion-weighted MR Imaging: A Closer Step Toward the "Holy Grail" of Tissue Characterization?, Radiology; 207:305-307.

15. Castillo M, Arbelaez A, Smith JK, et al., (2000): Diffusion-weighted MR imaging offers no advantage over routine non-contrast MR imaging in the detection of vertebral metastases. AJNR;21:948-953.

16. Shih TT, Huang KM, Li YW (1999): Solitary vertebral collapse: distinction between benign and malignant causes using MR patterns. J Magn Reson Imaging; 9:635-642.

17. Chan JH, Peh WC, Tsui EY, et al., (2002): Acute vertebral body compression fractures: discrimination between benign and malignant causes using apparent diffusion coefficients. Br J Radiol; 75:207-14.

18. Jung HS, Jee WH, Mc Cauley ThR, et al., (2003): Discrimination of Metastatic from Acute Osteoporotic Compression Spinal Fractures with MR Imaging. RadioGraphics; 23:179-187.

19. Zhou XJ, Leeds NE, McKinnon GC, Kumar AJ (2002). Characterization of benign and metastatic vertebral compression fractures with quantitative diffusion MR imaging. AJNR Am J Neuroradiol 2002; 23: 165_70.
20. Herneth AM, et al., (2002): Bone metastases: new trends in diagnostic imaging. Wien Med Wochenschr Suppl;113:92-4.

21. Fawzy F, Tantawy HI , Ragheb A, et al., (2013). Diagnostic value of apparent diffusion coefficient to differentiate benign from malignant vertebral bone marrow lesions. The Egyptian Journal of Radiology and Nuclear Medicine (2013) 44, 265271.

22. Baur A, Stabler A, Arbogast S, et al., (2002): Acute osteoporotic and neoplastic vertebral compression fractures: fluid signat MR imaging. Radiology;225(3):730-5.

23. Byun WM, (2001): Diffusion-weighted MR imaging of vertebral bone marrow: Differentiation of degenerative spines and spondylitis involving to bone marrow adjacent to end plates, Proc. Intl. Soc. Mag. Reson. Med;9:1626.

24. Jain AK, Sreenivasan R, Saini NS, et al., (2012): Magnetic Resonance evaluation of tubercular lesion in spine. International Orthopaedics (SICOT); 36:261-269.

25. Pui MH, Mitha A, Rae WID, et al., (2005): Diffusion-weighted magnetic resonance imaging of spinal infection and malignancy. J Neuroimaging;15(2):164-70.

26. Long SS , Yablon CM , Eisenberg RL, (2010): Bone Marrow Signal Alteration in the Spine and Sacrum. AJR; 195:W178-W200.

27. Hay MC, Paterson D, Taylor TFK (1978): Aneurysmal bone cysts of the spine. J Bone Joint Surg Br;60:406-411.

28. Leeds NE, Kumar AJ, Joe ZX, et al., (2000): Magnetic resonance imaging of benign spinal lesions simulating metastasis: role of diffusionweighted imaging. Top Magn Reson Imaging; 11(4):224-34.

29. Matrawy KHA, El-Nekeidy AZ, El-Sheridy HG, (2013): Atypical hemangioma and malignant lesions of spine: Can diffusion weighted Magnetic Resonance Imaging help to differentiate?. The Egyptian Journal of Radiology and Nuclear Medicine; 44:259-263.

30. Taskin G, Incesu L, Aslan K. The value of apparent diffusion coefficient measurements in the differential diagnosis of vertebral bone marrow lesions. online.journals.tubitak.gov.tr.

31. Byun WM, (2001): Diffusion-weighted MR imaging of vertebral bone marrow: Differentiation of degenerative spines and spondylitis involving to bone marrow adjacent to end plates, Proc. Intl. Soc. Mag. Reson. Med;9:1626.

32. Ballon D, et al., (2004): Imaging therapeutic response in human bone marrow using rapid whole-body MRI. Magn Reson Med;52(6):12348.

33. Mubarak F, Akhtar MW, (2011): Acute vertebral compression fracture: Differentiation of malignant and benign causes by diffusion weighted magnetic resonance imaging. J Pak Med Assoc.;61(6):555-8. 
|الملخص العربي

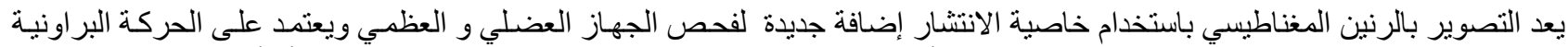

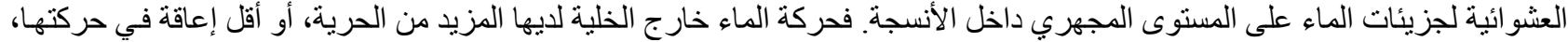

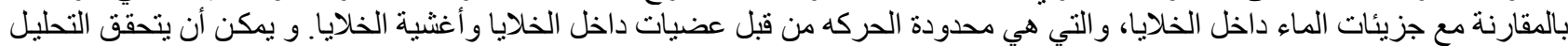

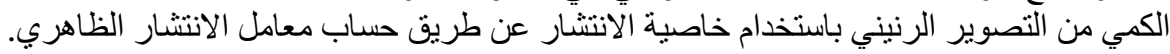

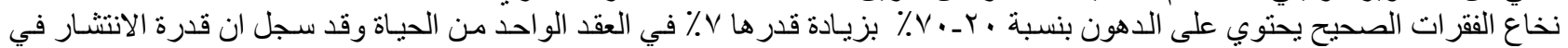

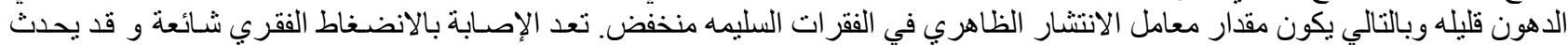

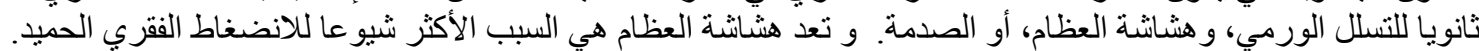

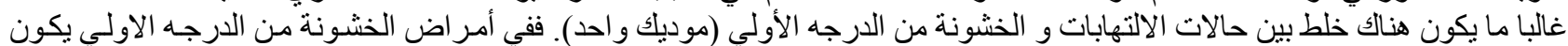

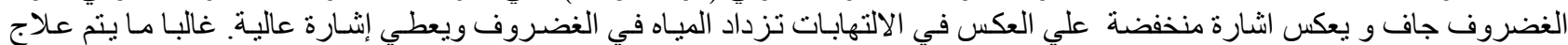

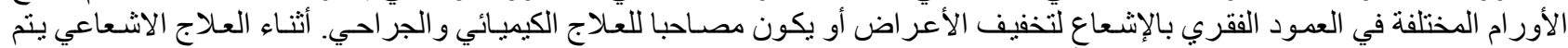

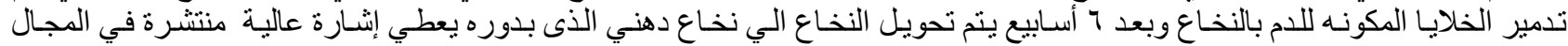

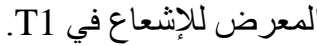

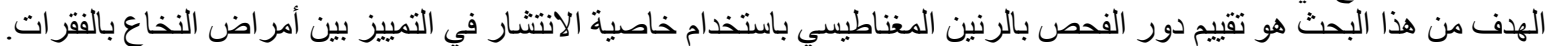

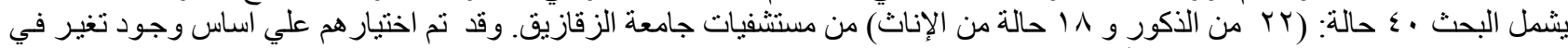

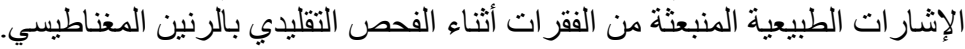

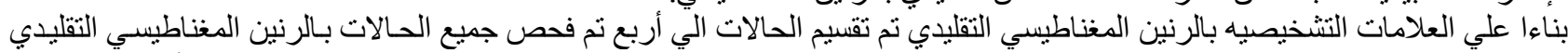

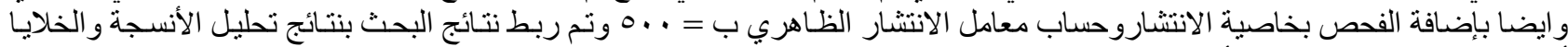

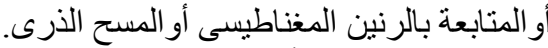

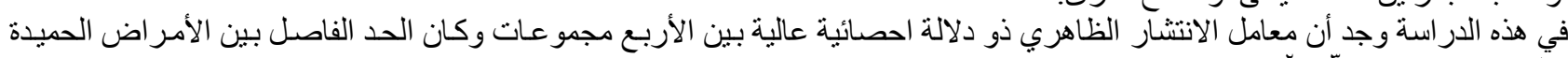

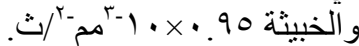

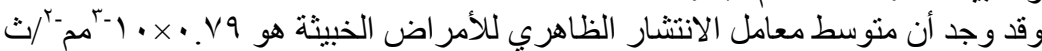

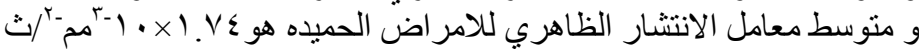

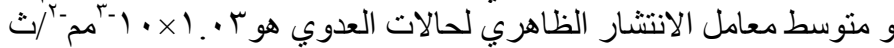

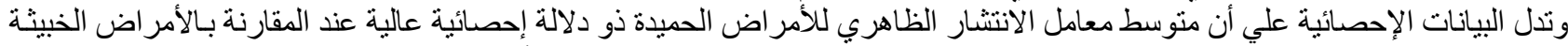

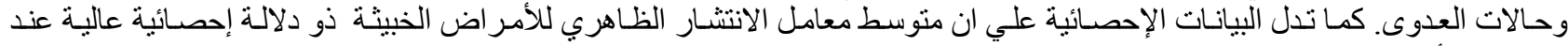

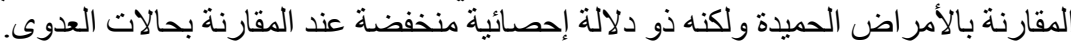
كما وجد أنه لا توجد دلالة إحصائية لمتوسط معامل الانتشار الظاهري بين الأسباب المختلفة للامر اض الخبيثة الخدة ، وأيضـا ببين الأسباب المختلفة الملأمر اض وجأ الحميدة.

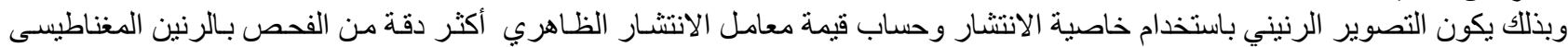

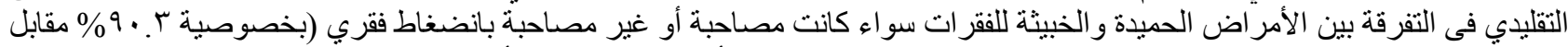

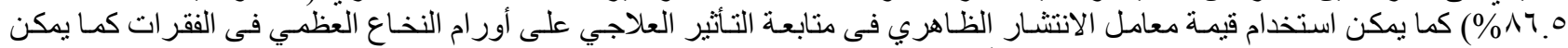

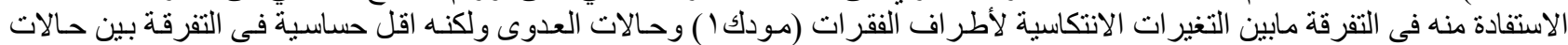

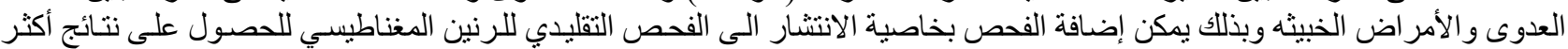

